\title{
FORMAÇÃO DOCENTE PARA UTILIZAÇÃO DE AMBIENTE VIRTUAL DE APRENDIZAGEM NO ENSINO SUPERIOR
}

\author{
CHAPECÓ/SC MAIO/2018
}

\author{
Juliane Colling - UCEFF - juliane@uceff.edu.br \\ Velcir Barcaroli - UCEFF - velcir@uceff.edu.br \\ Taiane Tais Habitzreiter - UCEFF - taiane@uceff.edu.br \\ Vanessa Oliveira de Alencar - UCEFF - vanessa.nead@uceff.edu.br \\ Adriano Kolakowski - UCEFF - revisor@uceff.edu.br \\ José Sérgio Boita Junior - UCEFF - video@uceff.edu.br
}

Tipo: Relato de Experiência Inovadora (EI)

Categoria: Conteúdos e Habilidades

Setor Educacional: EDUCAÇÃO SUPERIOR

\begin{abstract}
RESUMO
A cada dia a forma de fazer ensino tem se modernizado. Com a educação a distância, a necessidade de dominar ferramentas e plataformas digitais por parte dos docentes passou a ser uma necessidade. A formação docente nos dias atuais deve ser uma constante, já que a evolução tecnológica ocorre em uma velocidade cada vez maior. Neste sentido, o propósito deste trabalho é apresentar ações tomadas pela equipe do Núcleo de Educação a Distância (NEAD) da UCEFF, para a formação docente acerca da utilização do ambiente virtual de aprendizagem no ensino superior. $A$ formação envolve desde ações de conscientização da necessidade da utilização dessas novas tecnologias até oficinas práticas com temas específicos. Observou-se que, com essas formações, a utilização do ambiente virtual como apoio à disciplinas presenciais teve um crescimento exponencial $e$ os professores têm demandado cada vez mais atividades no ambiente virtual.
\end{abstract}

Palavras-chave: formação docente; ambiente virtual de aprendizagem; ensino híbrido 


\section{Introdução}

Os recursos educacionais e metodologias de ensino têm passado por mudanças e evoluções constantes com o objetivo de proporcionar novas experiências formativas para estudantes, desde o ensino fundamental até sua formação profissional no ensino superior. No entanto, para que essas inovações cheguem até os alunos, é de fundamental importância que os professores tenham possibilidade de se inteirar dos novos recursos digitais e receber formação continuada.

Tendo em vista essas mudanças e a necessidade de atualização constante de conhecimentos dos professores, a UCEFF, instituição de ensino superior privado do Oeste Catarinense, organiza periodicamente atividade de formação docentes. No ano de 2017, elas foram voltadas especialmente para as possibilidade pedagógicas e metodológicas de uso de recursos digitais no desenvolvimento e apoio às atividades das disciplinas, especialmente por meio do uso de um ambiente virtual de aprendizagem.

Organizaram-se, assim, ações efetivas de formação docente de forma que elas proporcionem aos professores novos conhecimentos e experiências práticas sobre o uso de recursos digitais em suas aulas. Este relato de experiência inovadora descreve algumas atividades realizadas e as estratégias de formação docente desenvolvidas com vistas a ampliar o uso de metodologias ativas mediadas por tecnologia e pelo uso do ambiente virtual no desenvolvimento de atividades de disciplinas presenciais e semipresenciais.

\section{Contextualização}

A UCEFF é uma instituição de ensino superior privado do Oeste Catarinense, atuando em três campi nas cidades de Chapecó e Itapiranga. A instituição oferece atualmente 17 cursos de graduação, 31 cursos de pós-graduação, além de atividades de extensão e iniciação científica. Uma das atividades de extensão de grande relevância para a instituição é o programa UCEFF na Escola, que atende escolas públicas e privadas de toda a região oeste catarinense e noroeste do Rio Grande do Sul, promovendo palestras e oficinas para alunos, pais e professores.

A instituição é constituída pelo Centro Universitário FAl de Itapiranga, criado em 2000 como FAl Faculdades. E pela Faculdade Empresarial de Chapecó, que atua na educação superior chapecoense desde 2009. A partir de 2018, as duas unidades passaram a atuar sob a marca UCEFF (Unidade Central de Educação FAI Faculdades\Faem Faculdades) e juntas tornaram-se a maior instituição privada de 
ensino superior do Oeste Catarinense.

O crescimento institucional da UCEFF está baseado na tecnologia e na alta gestão, impulsionando a formação de cidadãos inovadores, éticos e empreendedores. A UCEFF acredita que a evolução está na força do conhecimento, na qualidade de ensino, no envolvimento das pessoas e em alterar o estado de consciência de seus alunos e colaboradores. Tem como missão a formação profissional, científica e humana, voltada para o desenvolvimento regional.

A história da educação a distância (EaD) na UCEFF iniciou no ano de 2008 quando a IES decidiu que iniciaria a oferta de disciplinas semipresenciais. Na oportunidade os membros do Conselho Superior aprovaram uma resolução para oferta de disciplinas semipresenciais nos cursos de Administração e Ciências Contábeis. No ano seguinte, foi constituído o Núcleo de Educação a Distância (Nead) com o objetivo de implantar as disciplinas semipresenciais, acompanhar o desenvolvimento das atividades e pesquisar sobre as possibilidades da modalidade a distância no âmbito institucional e, ainda, capacitar os docentes para as atividades relacionadas à EaD. Atualmente, todos os cursos da instituição, em ambas as unidades, possuem disciplinas desenvolvidas na modalidade virtual.

Desde 2012, passou-se a utilizar o Ambiente Virtual de Aprendizagem Moodle como plataforma de ensino e aprendizagem, tanto no desenvolvimento das disciplinas semipresenciais quanto no apoio às disciplinas presenciais. O Ambiente Virtual de aprendizagem passou por processo de customização com a utilização de temas e personalização de layout. Desde então, o uso do ambiente virtual cresceu ano a ano, conforme apresentam os gráficos a seguir.

Gráfico 1: Evolução de Uso do Ambiente Virtual de Aprendizagem 2012 a 2018

\section{Uso do Ambiente Virtual de Aprendizagem 2012 a 2018}

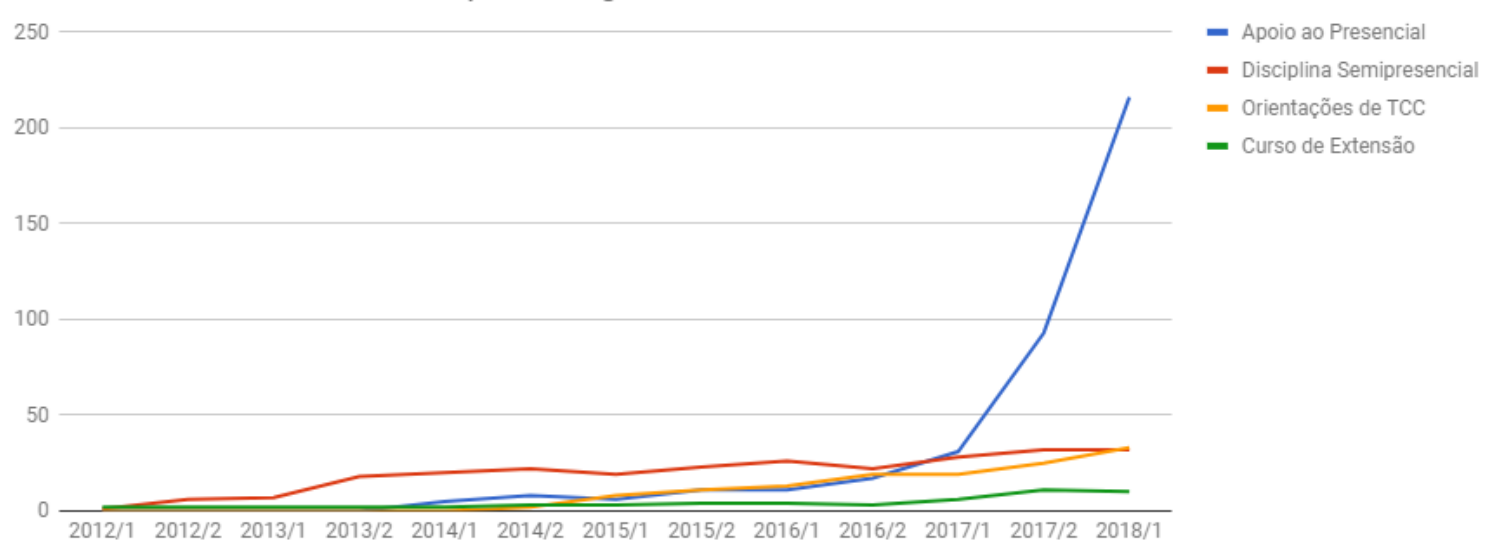


Percebe-se que o uso do Ambiente Virtual como recurso de apoio também em disciplinas presenciais teve um grande crescimento a partir do ano de 2017. Nesse ano foram realizadas diversas formações com docentes da instituição para apresentar recursos e metodologias de uso deste ambiente no desenvolvimento das atividades das disciplinas. Esta ampliação do uso do ambiente virtual no desenvolvimento das atividades educacionais na instituição só foi possível por meio da capacitação contínua dos docentes, dando-Ihes a oportunidade de conhecer os recursos disponíveis e as possibilidades pedagógicas e metodológicas de utilização na potencialização das atividades de ensino e aprendizagem em diferentes cursos e disciplinas.

A partir das experiências desenvolvidas ao longo dos anos com a oferta das disciplinas semipresenciais e da evolução e consolidação da utilização do ambiente virtual de aprendizagem, a Direção da UCEFF, em 2016, tomou a decisão de que havia chegado o momento de solicitar o credenciamento para oferta de cursos de graduação na modalidade a distância. Sendo assim, foi instituída uma equipe multidisciplinar para atuar junto ao Nead, responsável pela gestão dos projetos que envolvem oferta de EaD na UCEFF.

Tendo em vista a crescente aproximação entre o modelo tradicional e virtual, visualizando a possibilidade de um caminho híbrido, o ano de 2016 foi dedicado ao aprofundamento do conhecimento acerca de recursos, metodologias e experiências na área da educação a distância, educação híbrida e metodologias ativas mediadas por tecnologia. A partir desse conhecimento, organizaram-se diversas ações de formação docente no decorrer do ano de 2017, buscando desenvolver com os professores uma cultura interna de inovação educacional, utilizando-se os diferentes recursos para atingir os objetivos pedagógicos a fim de formar profissionais que atendam às necessidades de conhecimento, competências e habilidades esperadas no mercado de trabalho e na sociedade. A seguir, são apresentadas algumas das atividades formativas desenvolvidas neste processo.

\section{Atividades de formação docente}

A UCEFF desenvolve atividades de capacitação e formação aos seus docente por meio do Centro de Aperfeiçoamento Docente - CAD. Considerando as experiências já realizadas e a percepção das principais dificuldades e necessidades de conhecimento dos docentes, foram desenvolvidas diferentes atividades formativas no decorrer do ano de 2017, destacando-se neste relato as atividades voltadas ao uso de recursos virtuais e ensino híbrido. Por meio de um planejamento conjunto das duas unidades da instituição, todas as atividades desenvolvidas foram realizadas tanto em Chapecó quanto 
Itapiranga.

Como atividade de abertura do semestre, o CAD promoveu a palestra "7 Entendimentos Necessários para a Docência Universitária do Século XXI: Tudo é Relacionamento", com Wille Muriel. Nessa atividade formativa, destacaram-se as competências e habilidades necessárias à docência no contexto atual englobando a necessidade de inovar em sala de aula, desenvolvendo novas formas de ensinar e aprender.

Também foram realizadas oficinas específicas para os docentes de disciplinas ofertadas na modalidade semipresencial, abordando o tema "Planejamento, Gestão e Avaliação de Disciplinas Semipresenciais". Essas oficinas são realizadas no início de todo semestre para novos professores, sendo conduzidas pela Direção de Ensino e Equipe do Nead, apresentando-se o Ambiente Virtual de Aprendizagem, os recursos disponíveis no ambiente, formas de avaliação das atividades e dicas para melhor andamento da disciplina. A capacitação permitiu aos professores das disciplinas semipresenciais conhecerem o ambiente virtual da instituição, assim como o formato como as suas aulas seriam postadas e disponibilizadas para os acadêmicos.

Em maio e junho foi realizada a formação "Conhecendo o Mundo Virtual da Aprendizagem: Possibilidades e Desafios em Tempos de Conectividade". Nela foram apresentados diferentes recursos virtuais disponíveis no Ambiente Virtual de Aprendizagem e diferentes metodologias pedagógicas, realizando a reflexão de como elas podem ser aplicadas de forma conjunta na prática docente. Após a apresentação dessas metodologias e recursos, os professores foram desafiados e planejar uma atividade pedagógica envolvendo determinado recurso e metodologia.

Imagem 1: Atividade Prática Desenvolvida na Formação de Docentes
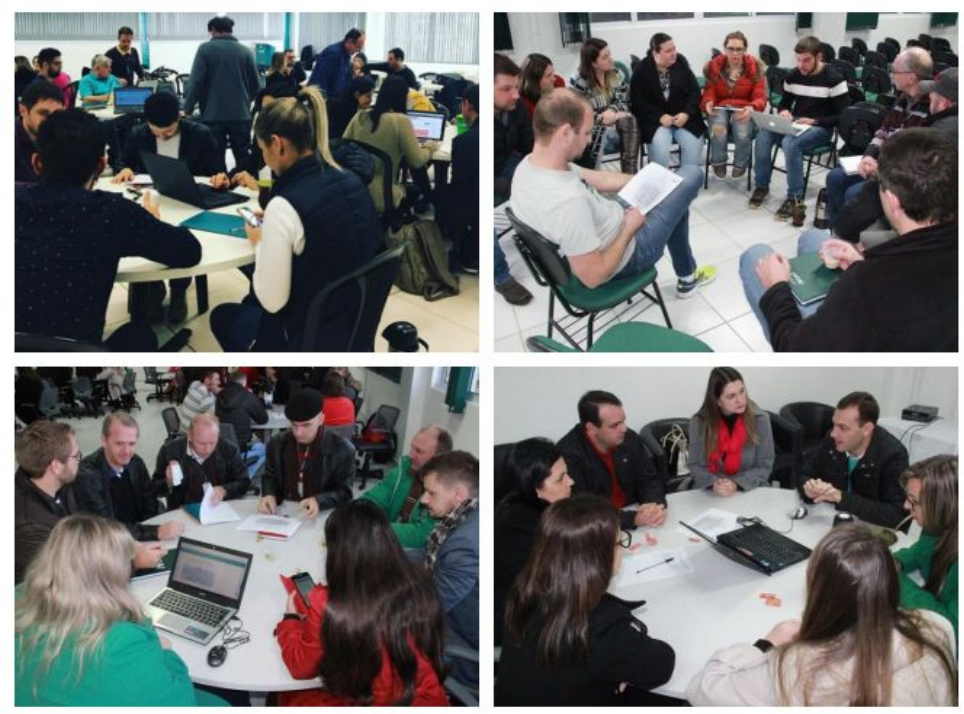
Nos meses de junho e julho foram realizadas oficinas de Produção de Videoaulas, destinada aos docentes da instituição. A oficina foi realizada de forma presencial, com aula teórica e prática, com continuidade de tarefas práticas compartilhadas no ambiente virtual do minicurso. O objetivo foi capacitar os docentes a produzirem seus próprios vídeos para utilização nas disciplinas como material complementar, trabalhando os processos de pré-produção, gravação e pós-produção audiovisual, além de técnicas de oratória e postura frente à câmera. Também foi produzido um vídeo de making of com imagens da primeira edição da oficina, disponível no link: https://vimeo.com/221326147/b00dc4beed.

Imagem 2: Oficina de produção de videoaulas.

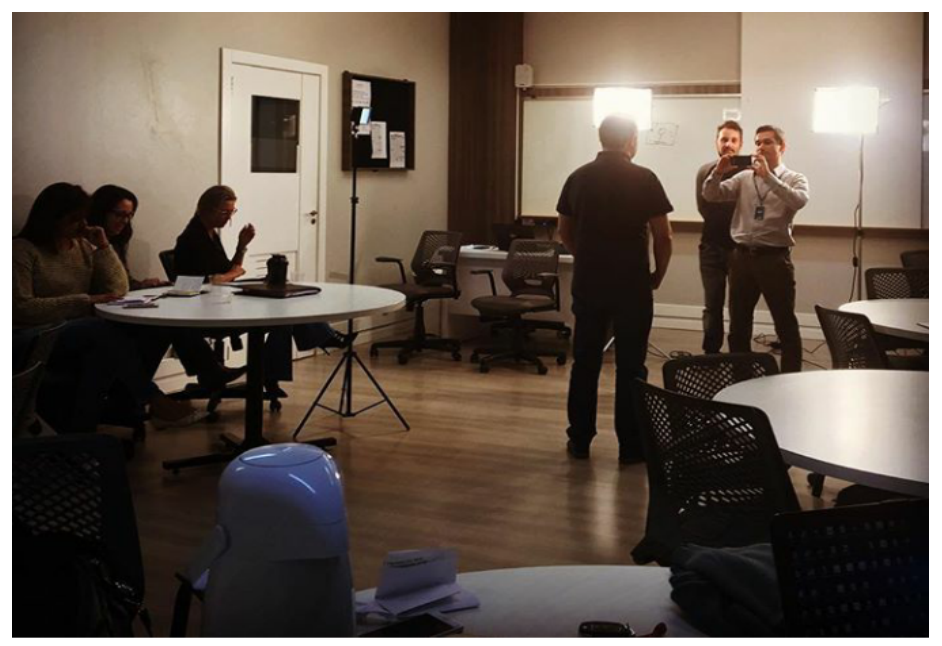

Além das formações docentes, também houve atividades desenvolvidas com colaboradores técnico administrativos. A formação teve um primeiro momento realizado de forma presencial, e teve sequência de forma on-line. O objetivo foi capacitar os funcionários técnicos-administrativos para que conheçam a estrutura e organização do ambiente virtual, bem como as funções de cada membro do Nead (coordenação, suporte técnico, professores, tutores etc.)

Imagem 3: Formação Nead com colaboradores técnico administrativos. 


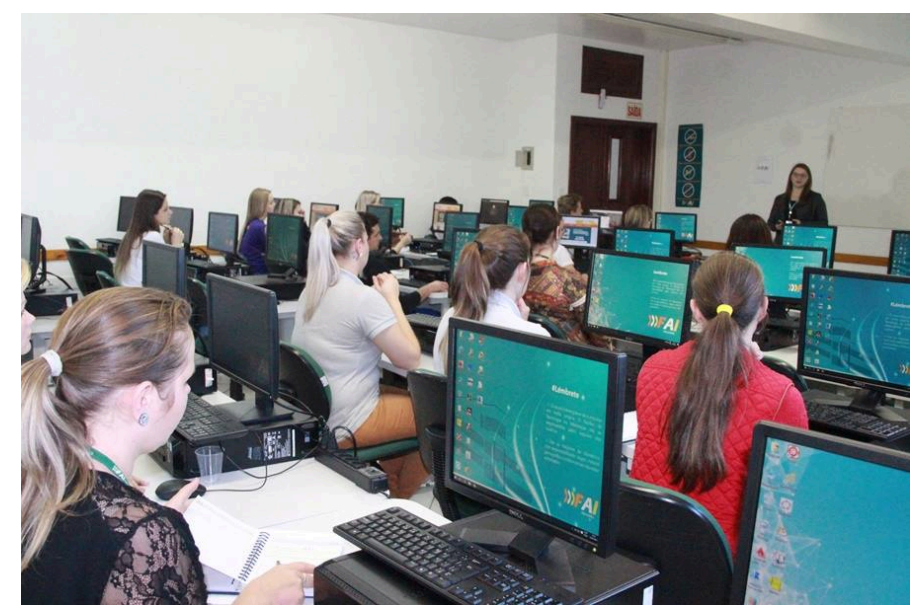

No mês de outubro, foi realizada a formação "Interagindo com as Ferramentas do Moodle". Essa formação foi realizada com o objetivo de apresentar e demonstrar de maneira prática os recursos disponíveis na plataforma Moodle para todos os professores da instituição, de forma a estimular a utilização do ambiente virtual de aprendizagem também no desenvolvimento de atividades das disciplinas presenciais. Possibilitou aos professores interagirem com o ambiente e pensar em possíveis situações em que se poderia aplicar e usar os recursos como apoio em suas aulas.

Imagem 4: Formação Interagindo com as Ferramentas do Moodle.

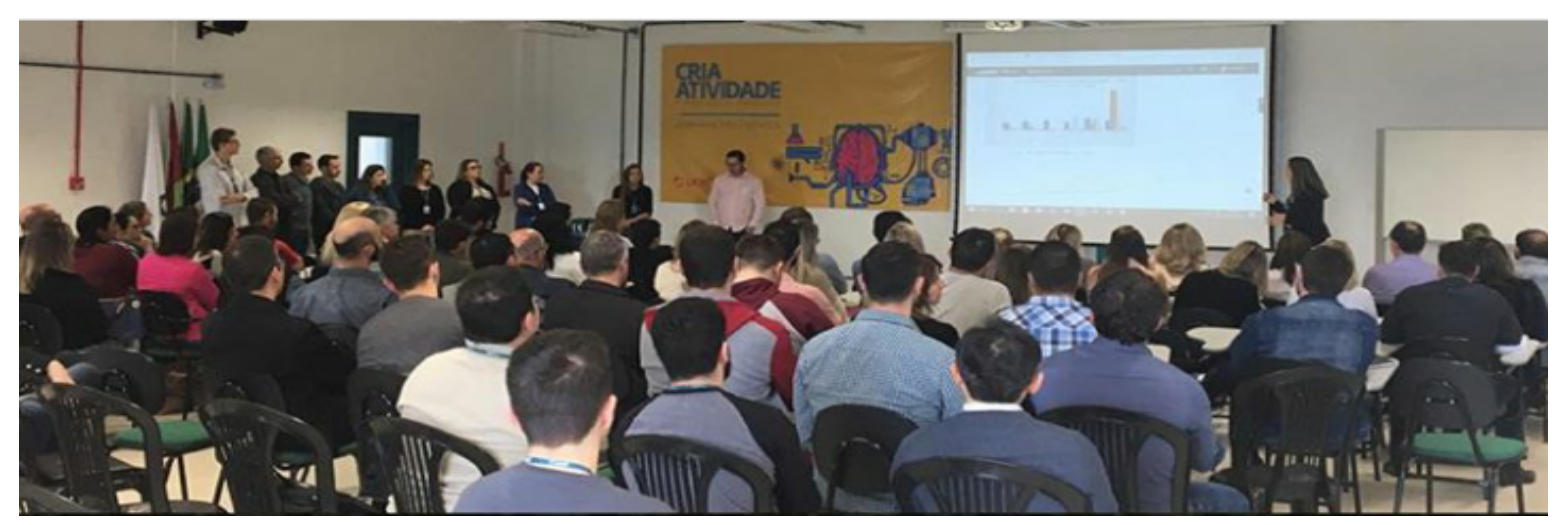

Já no mês de novembro, buscou-se trazer novos recursos virtuais que podem ser utilizados no desenvolvimento das aulas, na promoção de atividades mais interativas e aplicação de metodologias ativas de aprendizagem. Neste sentido, foi ofertada a formação "Recursos Virtuais de Aprendizagem", onde foram ofertadas diferentes oficinas, sendo que os professores podiam optar por um delas para participar. As oficinas abordaram diferentes recursos, como Kahoot, Powtoon, recursos Google (Drive, Documentos, Formulários), Office Mix, aTube Catcher, todas realizadas de forma presencial com apoio do ambiente virtual. Essa formação teve como objetivo apresentar aos professores os diferentes recursos digitais que podem ser usados em sala de aula para torná-la mais atrativa e dinâmica. 
Imagem 5: Oficinas práticas realizada com professores.

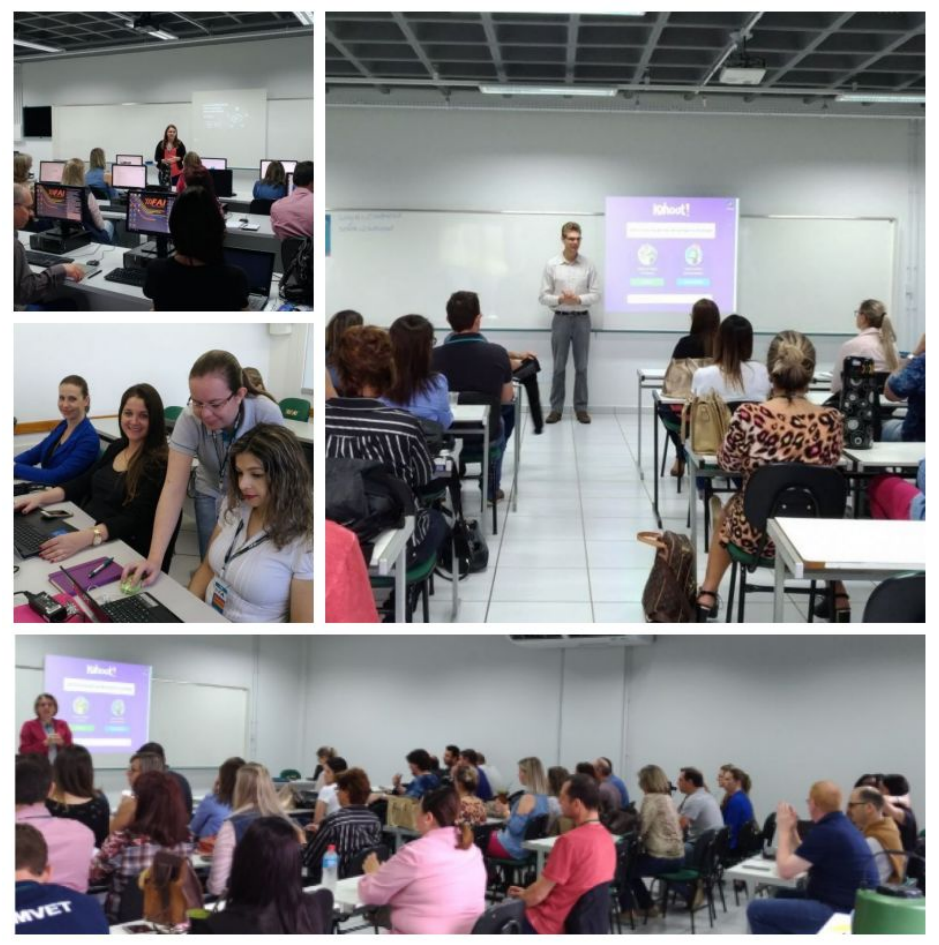

Também em novembro, foi promovido um momento para socializar experiências dos próprios docentes sobre o uso de recursos virtuais e ambiente virtual de aprendizagem. Esta atividade formativa foi denominada "Tertúlia Interativa: compartilhando experiências e vivências do uso do Ambiente Virtual". O objetivo desta atividade foi proporcionar um momento de troca de experiências entre os docentes da instituição, destacando metodologias e atividades pedagógicas que podem ser desenvolvidas com o uso dos recursos virtuais.

Imagem 6: Formação Docente Tertúlia Interativa

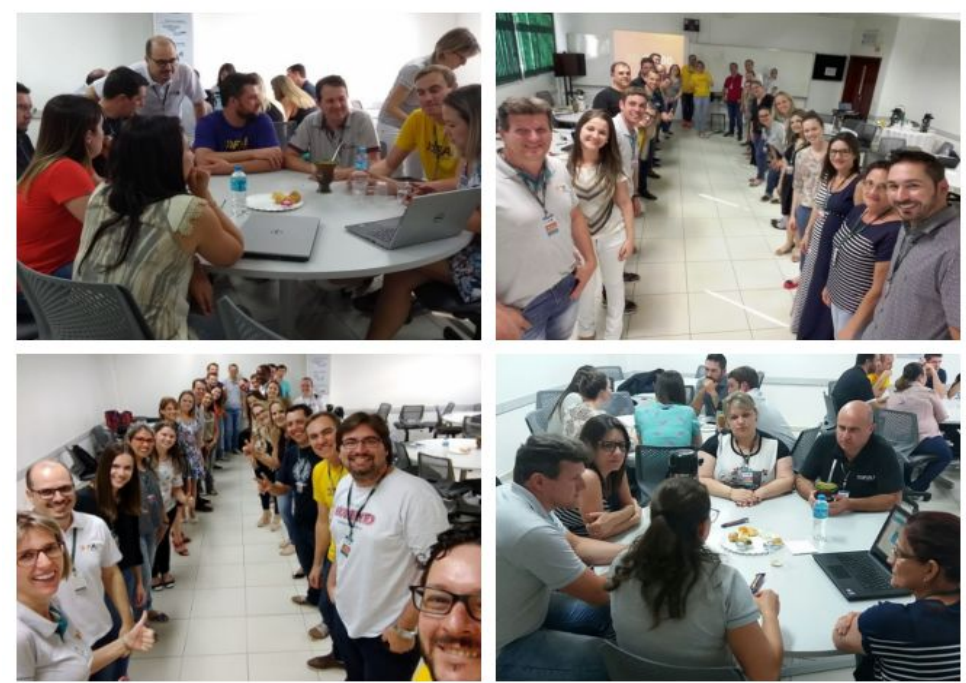


Encaminhando-se para o desenvolvimento de atividades que aproximam o presencial e o virtual, a UCEFF também buscou conhecer outras experiências inovadoras no Ensino Superior. Para tanto, proporcionou aos coordenadores e professores um momento de formação sobre Ensino Híbrido, com Ryon Braga, que compartilhou a experiência de trabalho com a metodologia de projetos da Uniamérica.

Imagem 7: Formação sobre Ensino Híbrido.

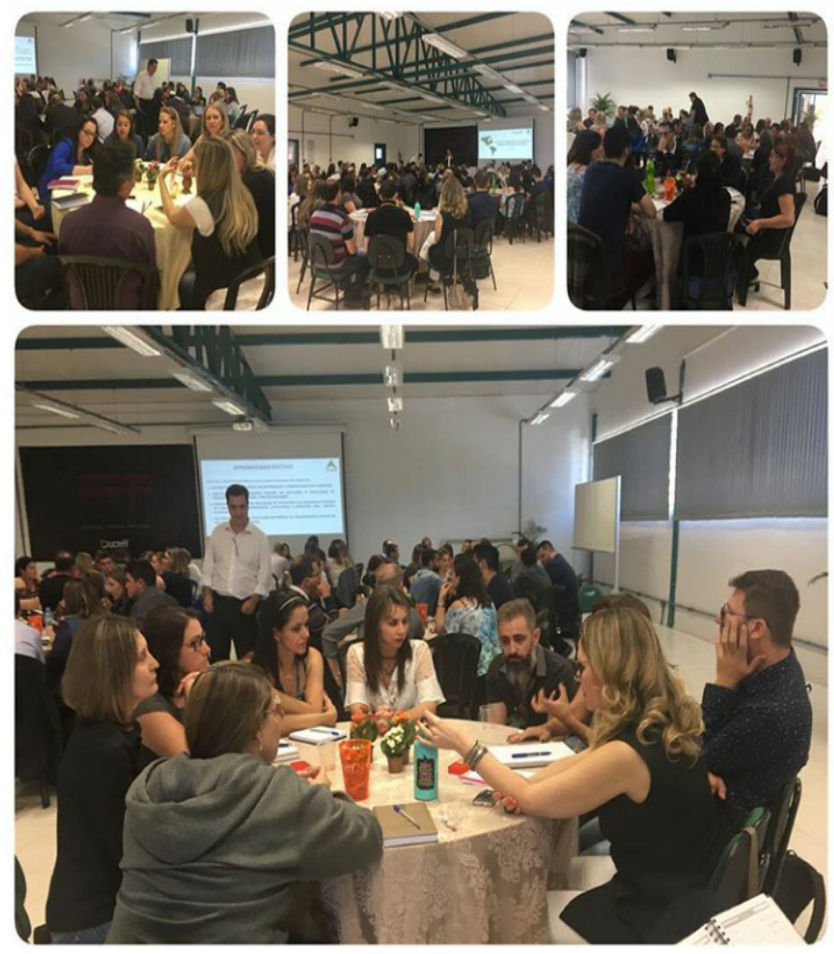

A partir de todas as formações e novas metodologias conhecidas, a UCEFF construiu de forma colaborativa um novo acadêmico, denominado Modelo LOOP, que permite maior autonomia do estudante ao traçar sua trajetória acadêmica. A fim de que os professores e colaboradores se integrassem a este novo modelo acadêmico, foram realizados diferentes momentos de socialização e sensibilização acerca do novo modelo acadêmico.

Uma das propostas do modelo LOOP é a realização de disciplinas de conhecimentos gerais ofertadas à todos os cursos simultaneamente, onde os acadêmicos podem optar quais disciplinas são necessárias para o seu momento de formação. Para tanto, também foi realizada em dezembro formação específica com docentes que iriam desenvolver estas disciplinas institucionais, denominada Formação DIs: Conectividade e Interação na Educação Híbrida, e fim de preparar as atividade desenvolvidas no ano de 2018.

Assim, encerraram-se as atividades formativas de 2017 acerca de novas metodologias e 
recursos virtuais, com foco na Educação Híbrida, a fim de preparar os docentes da UCEFF para atuar na formação de profissionais que atendam as necessidades do contexto atual e futuro.

\section{Considerações Finais}

Um bom professor tem papel fundamental na aprendizagem e vida profissional do seu aluno. Poder transitar entre as diversas tecnologias e ferramentas torna-se indispensável para melhorar a forma de ensino. A tecnologia por si só não garante a aprendizagem e a absorção do conteúdo por parte do aluno, mas se utilizada de forma adequada por professores qualificados, podem ser um diferencial.

As formações de professores para uso de ferramentas tecnológicas e do ambiente virtual não só intensificou a sua utilização, como também despertou novas necessidades a serem adequadas para os conteúdos ministrados por parte dos professores. A fim de atender essas necessidades, a equipe do Nead está sempre participando do processo formativo dos docentes da instituição, buscando novos recursos e metodologias que proporcionem aprendizagem efetiva.

A socialização das aplicações de novas metodologias e dos resultados alcançados por parte dos docentes tem sido fundamental. Motivados por esses resultados, novos professores se sentem encorajados ou desafiados a aplicar novas metodologias em suas aulas. Em virtude da especificidade de cada conteúdo ministrado, não existe um modelo pronto de sua aplicação, porém, baseado nas experiências socializadas, cada um pode criar estratégias pedagógicas para o processo de ensino aprendizagem.

Acredita-se que o objetivo de movimentar os professores a inovar em sua forma de trabalhar os conteúdos foi atingido. De forma geral, essas ações tiveram boa aceitação pela comunidade acadêmica. Cabe ressaltar que tiveram também alguns problemas isolados de resistência por parte dos alunos. Como trabalhos futuros, pretende-se criar instrumentos que possam medir os resultados de aprendizagem alcançados com a aplicação dessas novas metodologias. 